\title{
Surgery for Osteoarthritis of the Knee
}

\author{
J.R. Lewis ${ }^{1}$ and R.L. Carey Smith ${ }^{2}$ \\ ${ }^{1}$ Allograft Fellow, Perth Orthopaedic Institute, Perth \\ ${ }^{2}$ Trauma and Orthopaedic Surgery, Sir Charles Gairdner Hospital, \\ The University of Western Australia, Perth \\ Australia
}

\section{Introduction}

Osteoarthritis (OA) of the knee is a common joint disorder affecting nearly a third of the elderly population.

[Felson 1987] The chance of suffering from knee OA increases with advancing age. In a world with an aging population, the prevalence is set to increase further. Conservative management for Osteoarthritis of the knee is often successful and should always be considered initially. However, it is not uncommon for the situation to arise where conservative management has failed or indeed is futile. This chapter will outline, categorize and detail the surgical options available for knee OA. Key results from the literature will be used to demonstrate the current reasoning behind evidence-based practice in surgery for knee Osteoarthritis. In particular we shall focus on evidence comparing surgical options for knee OA.

\section{Definition, aetiology and diagnosis}

Osteoarthritis (OA), also known as osteoarthrosis and degenerative joint disease is a progressive disorder of the articular cartilage. The aetiology of knee OA is multifactorial. Contributory factors include age, sex, obesity and previous trauma. There is a genetic component to the aetiology of knee OA. It is thought that genetic variations lead to chondrocyte abnormalities resulting in osteoarthritis. [Valdes 2010] Twin studies have demonstrated an increase in prevalence independent of other confounding factors. [Spector 1996]

Diagnosis of knee OA is generally made from a combination of history, examination and radiographic findings. Plain radiographs are usually diagnostic, particularly if they are weight-bearing views. The four classic features are joint space narrowing, osteophyte formation, subchondral sclerosis and the presence of subchondral cysts. Not all of these are required for the diagnosis to be made. In some situations, additional imaging in the form of Computer Tomography (CT), Magnetic Resonance Imaging (MRI) and isotope bone scans can be helpful in providing further diagnostic information.

\section{Basic science of articular cartilage}

Osteoarthritis is principally a disorder of articular cartilage. The proteoglycan structure of articular cartilage can be damaged by trauma, or by enzymatic degradation secondary to 
inflammation or infection. If this occurs, the water holding ability of articular cartilage is disturbed. This in turn leads to progressive breakdown of the collagen meshwork exposing the subchondral bone beneath the articular cartilage. It is this exposure of bone, which is responsible for the symptoms of pain in OA.

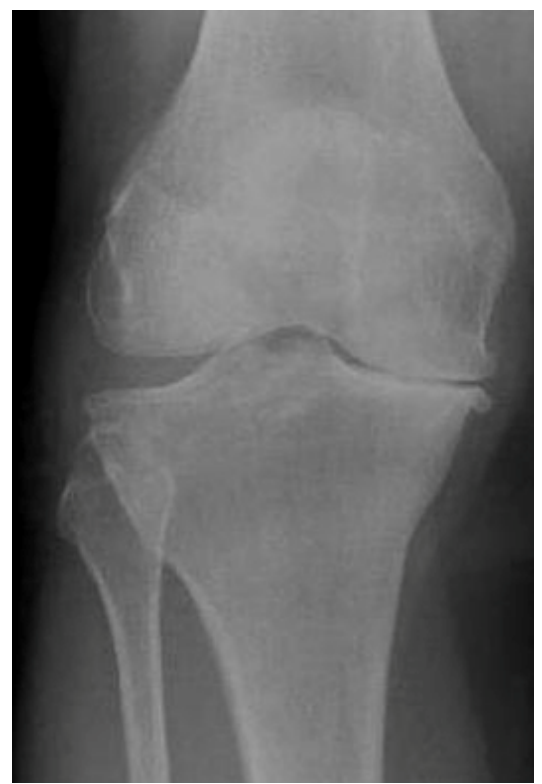

Fig. 1. Knee Osteoarthritis. Medial joint space narrowing, subchondral sclerosis and osteophyte formation.

Articular cartilage is avascular, aneural and alymphatic. Nutrition is derived by diffusion from the synovial fluid or via the blood vessels in the subchondral bone. Articular cartilage unfortunately cannot significantly repair once damaged. Partial thickness injuries do not heal as they stimulate only a minimal reaction in adjacent chondrocytes. Full thickness injuries penetrating the subchondral bone cause bleeding and heal with fibrocartilage as opposed to hyaline cartilage. Unfortunately, the mechanical properties of fibrocartilage are inferior to the specialized hyaline cartilage. The above-described mechanism of fibrocartilage production is the surgical goal of the marrow stimulation techniques, which will be described later.

\section{When is surgical intervention warranted in knee OA?}

Initial treatment of knee $\mathrm{OA}$ is with non-operative measures. When these measures fail, surgical options can be considered. The choice of procedure is based on the symptoms, the severity of $\mathrm{OA}$ and patient factors such comorbidities and physical demands on the knee.

The radiological findings are helpful in making an overall assessment of the patient, but do not dictate the treatment option alone. Many patients have severe radiological OA changes but with minimal symptoms. Similarly, some patients can be severely disabled by their knee OA symptoms with minimal changes on plain radiographs. 
Pain that is not responding to conservative measures along with decreasing function and mobility are the predominant features in the history that help guide when surgical treatment is required. Inability to sleep due to pain is used by many surgeons as a guide, but occasionally progressive deformity or instability symptoms dictate when the time is chosen for surgery.

There is no globally accepted timing point for surgery to be performed. Patient and surgeon factors along with availability of local resources all play their part.

This chapter will identify and discuss the surgical treatment options in knee OA.

\section{Surgical options}

\subsection{Arthroscopy}

Arthroscopy or "key hole" surgery involves the examination and treatment of intra-articular conditions of the knee. Small incisions or portals are made to allow the insertion of an arthroscope. A camera within the arthroscope, a fibre optic light source and irrigation allow visualization of the articular surfaces of the knee. Small instruments that are capable of probing, cutting, shaving and ablating can be passed through the portals to allow assessment and treatment of the osteoarthritic knee.

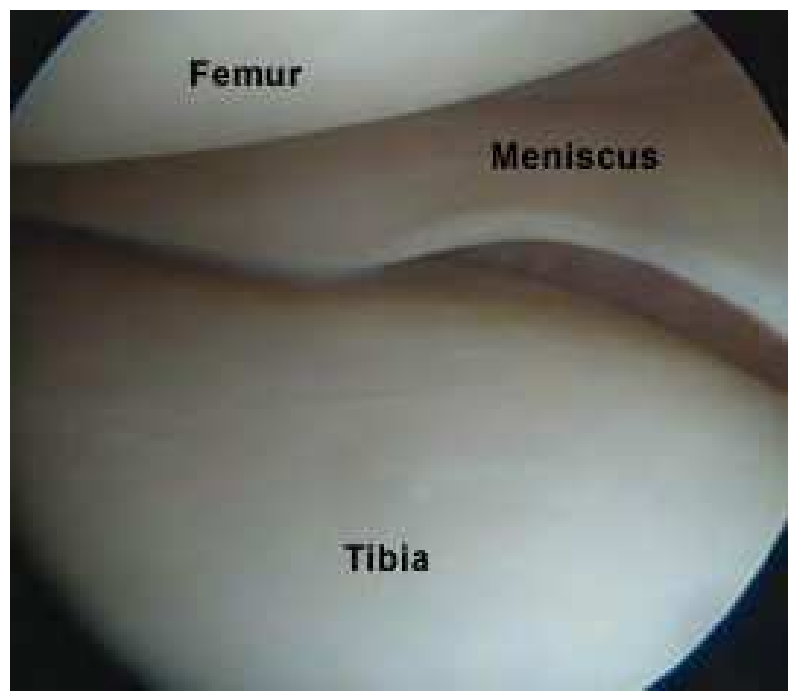

Fig. 2. Normal knee arthroscopic appearances

\subsubsection{Classification of cartilaginous lesions}

In 1961, Outerbridge [Outerbridge 1961] detailed a grading for patellar chondral lesions. Since then it has become accepted for lesions in other areas of the knee and remains a useful classification in the assessment of cartilaginous lesions of the knee.

Grade 1: Softening and swelling

Grade 2: Fragmentation and fissuring of 0.5 inch or less

Grade 3: Fragmentation and fissuring of 0.5 inch or more

Grade 4: Erosion of cartilage to bone 


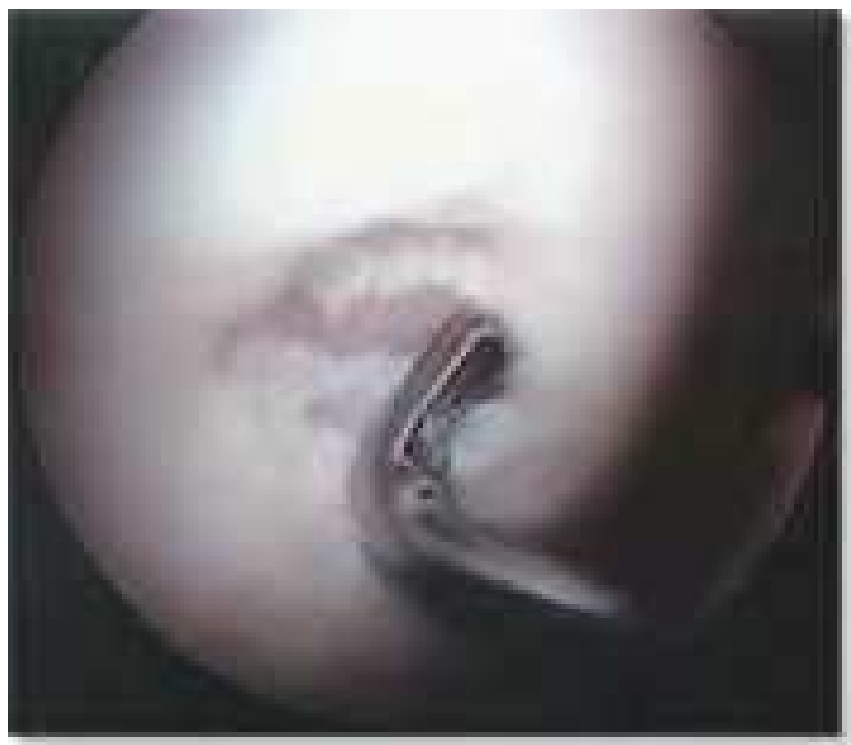

Fig. 3. Erosion of cartilage to bone. Medial femoral condyle.

\subsubsection{Arthroscopic lavage and debridement}

Arthroscopic lavage involves simply irrigating and washing out the knee joint. The lavage effect was first noted by Burman in 1934. [Burman 1934] Theoretically, it has been proposed that lavage is effective by removing debris and inflammatory cytokines that can cause synovitis. [Chang 1993] [OgilvieHarris 1991]

Arthroscopic debridement can remove loose chondral flaps. The removal of mechanical irritants by debridement of any roughened surface was pioneered by Magnuson in 1941 . [Magnuson 1941]

In well-selected middle-aged patients with grade 3 or 4 changes in the medial femoral condyle, a better outcome can be expected with arthroscopic debridement as opposed to arthroscopic lavage. [Hubbard 1996]

It remains controversial as to whether arthroscopic lavage or debridement has a significant role to play in the treatment of knee OA. [Zhang 2007] [Zhang 2008] [Zhang 2010]

Moseley demonstrated no significant benefit to arthroscopic lavage or debridement compared to placebo surgery. [Moseley 2002] The placebo effect was also shown to be significant in the treatment of OA in a systematic literature review. [Zhang 2008a]

A recent Cochrane review of arthroscopic debridement and lavage concluded from these that the procedure has no benefit for OA arising from mechanical or inflammatory changes. [Laupattarakasem 2008]

Despite the lack of evidence in favour for this procedure, it is easy to see why it continues to part of the surgical armamentarium for knee OA for many patients and surgeons. It is evident that it cannot prevent the progression of OA, but it may offer some temporary symptomatic relief. It is a low risk procedure with a short postoperative recovery and doesn't "burn any bridges" in terms of further procedures. 


\subsubsection{Arthroscopic bone marrow stimulating techniques}

The following procedures are not curative. They all aim to create bleeding which in turn will produce a fibrin clot on the exposed bony surface. Undifferentiated cells from the bone marrow proliferate with an end result a fibrocartilage (scar tissue). The procedures do not address the issue of why a weight bearing area of articular cartilage has been denuded. If there is an underlying element of instability or malalignment, the fibrocartilage layer filling the defect is likely to fail.

\subsubsection{Drilling}

Pridie first described this technique using an arthrotomy incision. [Pridie 1959] He used a 0.25 inch drill bit to penetrate the vascular cancellous bone beneath the sclerotic subchondral lamina. This technique has been adapted to the use of a kirschner wire via arthroscopic portals. Two studies using this technique in rabbits have failed to demonstrate long-term coverage of the denuded bone. [Meachim 1971] [Mitchell 1976]

\subsubsection{Abrasion arthroplasty}

In this technique a motorized burr is used to create an intracortical abrasion in areas where the chondral surface is deficient. Similar in nature to the drilling technique, the process causes localized bleeding and consequent healing with fibrocartilaginous tissue. During the immediate postoperative phase, the healing fibrocartiaginous tissue is protected from shearing forces by a period of non-weight bearing for the patient.

One study found abrasion arthroplasty was beneficial in the short term in $60 \%$ of 110 patients who had full thickness cartilage defects in the knee. Better results were noticed in patients less than 40 years of age. [Friedman 1984]

A comparative 5 year retrospective review of 126 patients with unicompartmental osteoarthritis, undergoing arthroscopic treatment, demonstrated a satisfactory result in only $67 \%$ of 59 patients who had been managed with abrasion arthroplasty with debridement as opposed to a satisfactory result in $79 \%$ of 67 patients who had been managed with arthroscopic debridement alone. [Bert 1989]

\subsubsection{Microfracture}

This technique is currently the most widely accepted of the bone marrow stimulating techniques.

Microfracture is the process of making multiple small holes in an area of denuded articular surface with small picks by hand rather than using drills or pins under power. In this low energy technique the awl theoretically causes microfracture of the trabeculae rather than destruction of the bone. Steadman et al [Steadman 1997] describe the technique where the exposed bone is debrided of loose articular cartilage to a stable articular margin. The base of the defect should also be debrided to remove the calcified layer of cartilage. Three to four perforations per square centimeter are made at a depth of approximately $4 \mathrm{~mm}$ and spaced 3-4 mm apart. Post operatively range of movement exercises are encouraged, but weight bearing is restricted to protect the healing cartilaginous zone. Histological evaluation of the healed tissue following second look arthroscopy has demonstrated a hybrid of fibrocartilaginous and hyaline-like cartilage. [Bae 2006]

This is a relatively simple, low cost arthroscopic technique. Steadman [Steadman 2002] [Steadman 2003] reported $80 \%$ of 75 knees were improved by microfracture with respect to 
function and pain at a minimum of 7 years follow up. Other studies suggest a shorter duration of improvement. Kreuz et al found that in their 85 patients, a deterioration in results began at 18 months post surgery. They also reported that the clinical results appear age dependent with better results in patients less than 40 years of age. [Kreuz 2006]

With the development of chondrocyte implantation techniques, inevitably the question arises as to which technique is superior in terms of clinical results. Numerous studies have attempted to address this. A recent systematic review [Harris 2010] evaluated 7 studies [Basad 2010] [Basad 2004] [Knutsen 2007] [Knutsen 2004] [Saris 2009] [Saris 2008] [Kon 2009] comparing autologous chondrocyte implantation with microfracture. Intermediate term (with follow up times ranging from 1 to 5 years) clinical outcome analysis demonstrated a trend towards autologous chondrocyte implantation having improved outcomes as compared with microfracture.

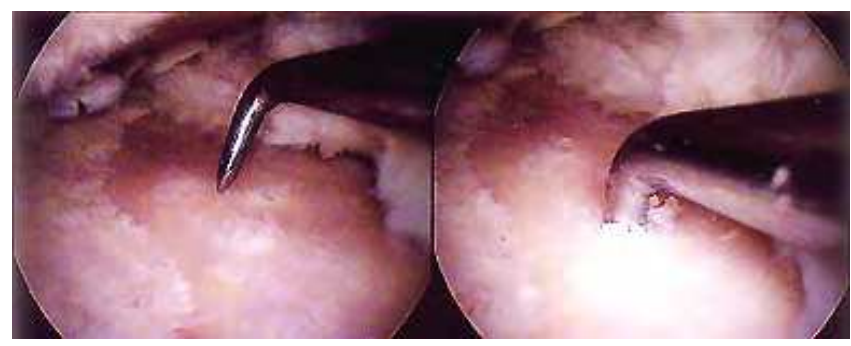

Fig. 4. Microfracture technique.

\subsubsection{Arthroscopic Osteochondral Autograft Transplantation System (OATS or Mosaicplasty)}

Transplantation of hyaline cartilage from one area of the knee to another will not heal to the underlying bone. An osteochondral graft provides a bony surface to anchor the attached cartilage to the recipient area. The bony area can then be replaced by creeping substitution. This technique was first described in 1993 by Matsusue et al. [Matsusue 1993] Single or multiple cylindrical plugs from a relatively non weight-bearing region of the knee are harvested. These plugs are then inserted into the chondral surface defect. It is possible to perform the procedure either as an open procedure or arthroscopically.

The main disadvantages are donor site morbidity and the limited options for donor site. The donor site is usually the edge of the patellar groove or the area just proximal to the intercondylar notch. Although larger grafts have been performed, [Karataglis 2005] the limited possible donor sites available, generally restrict the use of this technique to small focal areas of articular cartilage loss.

Outerbridge [Outerbridge 1995] demonstrated an improvement in knee function and symptoms at an average of 6.5 years following osteochondral grafts for defects of the femoral condyle. The procedure does not seem to disturb the main nutritional pattern of articular cartilage. The donor sites fill in with fibrocartilage.

Hangody [Hangody 2003] reported the results of a large series of mosaicplasty. 597 femoral condyles, 76 tibial plateau and 118 patellofemoral joints at up to 10 years postoperatively were assessed. Good or excellent results were reported in $92 \%, 87 \%$, and $79 \%$ of patients who underwent mosaicplasty of the femoral condyle, tibial plateau and patellofemoral joint respectively. 
When compared to other cartilage repair techniques, a randomized study by Gudas et al [Gudas 2005] demonstrated a more reliable improvement in clinical outcome with OATS compared to microfracture. In a recent systematic review [Harris 2010] autologous chondrocyte implantation and mosaicplasty were compared in 2 studies. [Dozin 2005] [Horas 2003] Analysis demonstrated equivalent clinical outcomes, but a more rapid treatment response was seen with the mosaicplasty patients.

\subsubsection{Autologous chondrocyte implantation}

In 1994 Brittberg [Brittberg 1994] described the technique whereby cultivated and proliferated autologous chondrocytes are re-implanted underneath a periosteal flap. An initial arthroscopy following visualization of the chondral defect provides the opportunity to harvest chondrocytes with a small probe. The harvested cells are then grown in a monolayer culture enriched with growth factors over a 3-4 week period. The cells can be suspended in a liquid medium or cultured directly into a three-dimensional collagen scaffold which itself can be implanted. A collagen membrane now replaces the periosteal flap that was initially described. The second stage of the procedure is performed through an open arthrotomy. The main advantage of the procedure is the potential for the restoration of normal hyaline cartilage. The disadvantages are the need for 2 procedures and the cost of the cell culture.

Similar to other cartilage repair techniques, success depends on patient selection. The ideal candidate is a young patient, with a short duration of symptoms and an isolated small chondral defect. [Krishnan 2006]

Instability, malalignment and patellofemoral maltracking will almost certainly jeopardize the final result. An improvement over recent years in Magnetic Resonance Imaging techniques is helpful in patient selection and assessment. [Potter 2009]

Histological analysis studies [Roberts 2003] have demonstrated tissue which is hyaline-like, but the tissue is not morphologically or histochemically identical to normal hyaline cartilage and may include some fibrocartilage.

In a clinical review of 244 patients [Brittberg 2003] with 2-10 years' follow up, subjective and objective improvements were seen in high numbers of patients with femoral condyle lesions. There was a high percentage of good to excellent results (84-90\%) in patients with different types of single femoral condyle lesions while other types of lesions had a lower degree of success. Other reports have shown similar levels if success in terms of symptomatic improvement [Erggelet 2003] [Gillogly 2006]. However it has been suggested [Lohmander 2003] that results should be compared with other cartilage repair techniques in randomized trials.

In a randomized trial of 100 patients comparing autologous chondrocyte implantation (58 patients) with mosaicplasty (42 patients), Bentley [Bentley 2003] demonstrated a significant difference between the 2 groups with $88 \%$ excellent or good results in the autologous chondrocyte implantation group and $69 \%$ excellent or good in the mosaicplasty group. A recent systematic review [Harris 2010] comparing these two techniques, looked at two other studies [Horas 2003] [Dozin 2005] concluding that clinical outcomes were similar.

The same systematic review [Harris 2010] evaluated 7 studies [Basad 2010] [Basad 2004] [Knutsen 2007] [Knutsen 2004] [Saris 2009] [Saris 2008] [Kon 2009] comparing autologous chondrocyte implantation with microfracture. Intermediate term (with follow up times ranging from 1 to 5 years) clinical outcome analysis demonstrated a trend towards 
autologous chondrocyte implantation having improved outcomes as compared with microfracture.

Despite the increasingly widespread use of autologous chondrocyte implantation, it remains unclear as to whether there is a significant difference between this and other cartilage repair techniques. A Cochrane Database Systematic Review [Vasiliadis 2010] concluded that there was insufficient evidence to draw conclusions on the use of autologous chondrocyte implantation in the knee.

\section{$\mathbf{5 . 2}$ Osteotomy}

Osteotomies around the knee alter the weight-bearing axis of the lower extremity. The surgical goal is to unload the damaged compartment and to transfer the weight load from the affected areas by slightly overcorrecting into a valgus or varus alignment. The aims of the procedure are to reduce pain, slow the degenerative process and delay joint replacement.

The concept gained acceptance in the 1960s after studies by Jackson and Waugh [Jackson 1961]. They demonstrated that a correction in the knee deformity relieved the pain. Many surgeons believe that the mechanism for symptomatic improvement is entirely mechanical [Harris 1970]. Others believe that this biomechanical concept is spurious. Shaw and Moulton demonstrated in their biomechanical cadaveric study, that to unload the medial compartment, a valgus correction of 25 degrees would be required. [Shaw 1996]

During the 1960s and 1970s, the use of osteotomy was the recommended surgical treatment for osteoarthritis of the knee. As the mid term and long-term excellent results of knee replacements became apparent, the use of osteotomy became less widespread.

The advantages of osteotomy over total joint arthroplasty are the preservation of bone stock and intra-articular structures. The classic indication is an osteoarthritic knee with single compartment disease (most commonly the medial compartment) accompanied by a varus or valgus alignment. Patient selection is fundamental to achieving a satisfactory result. The knee should have a good range of movement. The patellofemoral joint should not be significantly involved. Ligamentous stability is ideal, but cruciate ligament instability is not an absolute contraindication. Combining an osteotomy with a cruciate ligament reconstruction is possible. Changing the slope of the proximal tibia at the time of the osteotomy can also improve cruciate ligament laxity. [Aqueskirchner 2002] [Paley 2000]

Osteotomies around the knee have generally been suited to young active patients in place of joint replacement. An osteotomy once united allows unlimited activity. The polyethylene is a cause for concern in highly active patients with knee joint replacements. High loads from running and jumping may exceed the tolerance of polyethylene. Repetitive loading may loosen or damage a total knee replacement.

In unicompartmental osteoarthritis, it is possible to correct the mechanical axis with different techniques. These include proximal tibia and supracondylar distal femoral osteotomies. Both can be performed with an additive (opening wedge) or subtractive (closing wedge) technique. Most commonly, the osteotomy is performed on the proximal tibia for varus medial compartment osteoarthritis. This can be a lateral closing wedge or a medial opening wedge osteotomy.

Traditionally, a closing wedge, valgising osteotomy was performed for medial compartment osteoarthritis. Described by Coventry [Coventry 1965], the osteotomy is made proximal to the tibial tuberosity and incorporates a fibula osteotomy also. 
One disadvantage of a lateral closing proximal tibial osteotomy is the associated risk of peroneal nerve injury at the time of fibula osteotomy. This is reported to be as high as $11 \%$. [Staubli 2003] Other concerns are the propensity for loss of bone stock, patella baja and leaving the joint line in an oblique position, making subsequent joint replacement more challenging.

For these reasons, the medial opening wedge osteotomy has gained in popularity.

\subsubsection{Outcome following high tibial osteotomy}

There are numerous studies available on the outcome following high tibial osteotomy. Differing techniques and evaluation methods make pooling and comparison of this data challenging. A Cochrane review [Brouwer 2007] concluded that there is "silver" level evidence that a valgising high tibial osteotomy improves knee function and reduced pain, but there is no evidence whether an osteotomy is more effective than conservative treatment.

Coventry describes good results in several studies. [Coventry 1979] [Coventry 1982] [Coventry 1993] Coventry also states that high tibial osteotomy not only improves the knee function, but also allows healing of the articular cartilage. [Coventry 1984]

Multiple studies have demonstrated that the early good results of high tibial osteotomy gradually deteriorate with time. A meta-analysis [Virolainen 2004] demonstrated good or excellent results in $75 \%$ of patients after 60 months and $60 \%$ of patients after 100 months. Unchanged and mild pain were defined as unsatisfactory results.

It is generally accepted that age is an important factor in predicting outcome. Patients greater than 50 years old are less likely to have a satisfactory result. [Naudie 1999] [Flecher 2006]

The degree of correction has repeatedly been shown to correlate with survivorship. Overcorrecting the femorotibial angle to more than 15 degrees has been shown to give a better clinical outcome, but the cosmetic appearance is generally not acceptable to patients. [Rudan 1990] Under correction is associated with a poorer outcome. [Naudie 1999] [Ivarsson 1990] [Matthews 1988] [Sprenger 2003]. Consequently, most surgeons aim for a correction of between 5 and 12 degrees.

\subsubsection{Closing versus opening wedge high tibial osteotomy}

For many years, the closing wedge osteotomy was considered the gold standard. Over recent years the medial open wedge osteotomy technique has been developed. This procedure is considered technically less demanding and more precise. The use of modern angular stable locking plates for fixation of the osteotomy makes the need for bone grafting potentially dispensable. [Lobenhoffer 2003] [Staubli 2003]. Long-term results for open wedge techniques, with modern implants using locking screws are not yet available. One randomized controlled trial [Brouwer 2006] comparing the two techniques reports at one year follow up, an improvement in knee function and pain in both groups but no significant differences. Until further studies become available, it is not possible to state which technique should be preferred.

\subsubsection{Total knee replacement after high tibial osteotomy}

Understandably, the outcome of Total Knee Replacement following High Tibial Osteotomy raises concerns amongst surgeons and patients. The two concerns generally raised, relate to 
the technical difficulty of total knee replacement following high tibial osteotomy and the whether there is a negative effect on functional outcome of total knee replacement if there has been a previous high tibial osteotomy.

It is generally accepted that Total Knee Replacement can be more challenging following lateral closing wedge High Tibial Osteotomy. [Mont 1994] [Karabatsos 2002] The difficulties relate to loss of bone stock, surgical exposure, obliquity of the joint line, soft tissue balancing and patella baja.

Amendola [Amendola 2010] reviewed all published data relating to this and concluded that there is no statistically significant difference between patients treated with a primary total knee replacement or with a total knee replacement following a high tibial osteotomy. A systematic review by Van Raaij [VanRaaij 2009] also concluded that previous osteotomy does not compromise subsequent total knee replacement.

There have been no studies reporting Total Knee Replacement results following opening wedge high tibial osteotomy.

\subsubsection{Unicompartmental knee arthroplasty versus high tibial osteotomy}

Although there is a large difference in the philosophy between these two procedures, the indications can overlap. Consequently, a number of comparative studies have been performed. Most of these studies compare Unicompartmental Knee Arthroplasty to lateral closing wedge high tibial osteotomy.

A retrospective review of 49 lateral closing wedge high tibial osteotomies and 42 unicompartmental knee arthroplasties reported $76 \%$ good results with Unicompartmental Knee arthroplasty and 43\% with high tibial osteotomy at 5-10 years. [Broughton 1986]
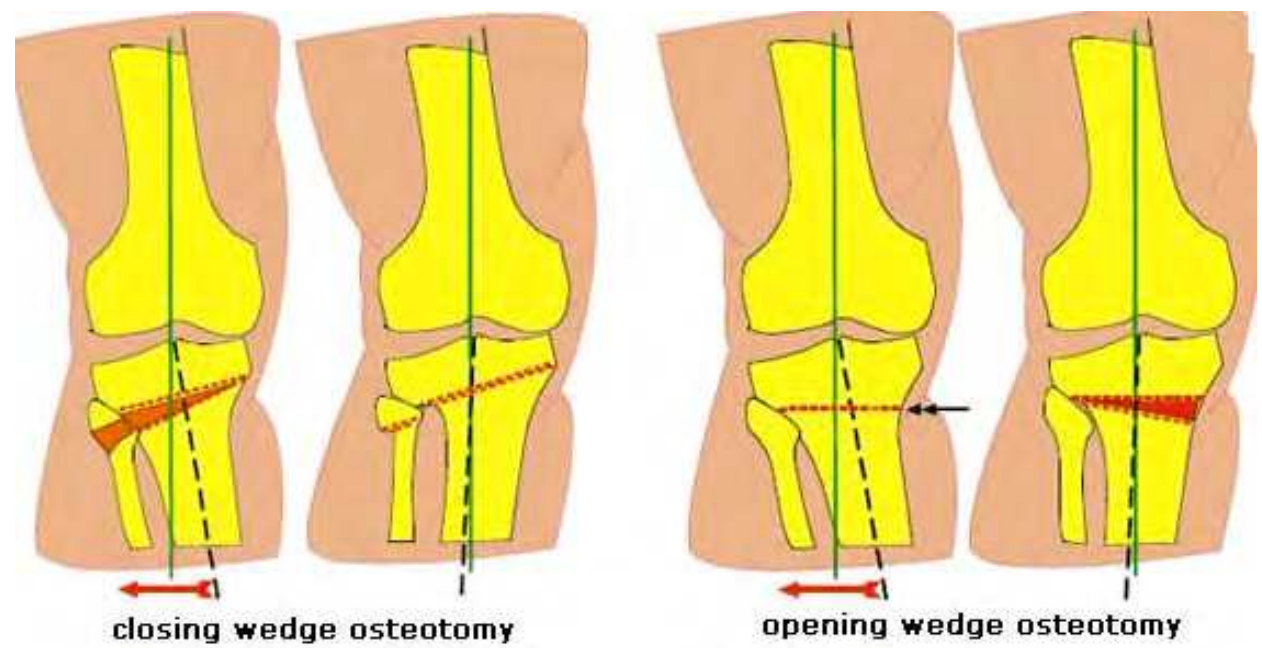

Fig. 5. Closing and opening wedge osteotomies of the proximal tibia

A prospective randomised comparison between 32 high tibial osteotomies and 28 unicompartmental knee arthroplasties reported improved long term success with unicompartmental knee arthroplasty with $77 \% 10$ year survival compared with $60 \%$ in the osteotomy group. [StukenborgColsman 2001] 
A comparison of 54 consecutive opening wedge high tibial osteotomies and 56 unicompartmental knee arthroplasties found no difference in the midterm clinical or radiological results. [Dettoni 2010]

The latest Cochrane review [Brouwer 2007] states that there is no significant difference in pain, function and gait analysis between HTO and UKA.

\subsection{Arthroplasty}

Arthroplasty or joint replacement is a well-accepted and effective treatment modality for advanced knee osteoarthritis. The number of knee arthroplasties performed has increased exponentially over the last few decades.

\subsubsection{History of knee arthroplasty}

Themistocles Gluck implanted a primitive hinge joint made of ivory in 1860. The next significant step was the acrylic Walldius hinge joint in 1951, followed by a cobalt and chrome implant in 1958. [Walldius 1953]

Gunston in the 1960s designed an unhinged knee that that incorporated separate medial and lateral condylar components. [Gunston 1971] Gunston recognized that the knee does not rotate on a single axis and has more complex kinematics than a simple hinge. By preserving the cruciate ligaments, the polycentric knee design allowed the femoral condyles to roll and glide on the tibia with multiple instant centres of rotation. The failure mechanism related to inadequate fixation of prosthesis to bone.

The so-called "kinematic conflict" arose as further designs became available. Some designers opting to follow Gunston's principle of attempting to recreate normal knee kinematics. Others opting for a conforming articulation and constraint. A highly conforming design acts like a simple hinge, which increases the torsional stress across the joint leading to loosening of the prosthesis.

Insall designed and introduced the Total Condylar Prosthesis at the Hospital for Special Surgery in 1973. This initial design did not attempt to recreate normal knee kinematics. Subsequently, the design was altered to improve knee range of movement. Improvements in component geometry, instrumentation, bearing materials and fixation techniques continue to be made.

\subsubsection{Indications and assessment for knee arthroplasty}

The functional impact of the knee osteoarthritis is the key factor in determining the timing of knee replacement surgery. Severity of symptoms are classically assessed by how disabling the pain is, noting a decreased walking distance, increased analgesic use and disturbance of sleep.

Examination should assess gait, limb alignment, range of movement and the neurovascular status of the limb. Other sources of knee pain such as the hip and lumbar spine should routinely be assessed to exclude dual pathology.

Up to date radiographs should be available including weight bearing anteroposterior views as well as a true lateral and skyline view. Radiographs of the ipsilateral hip are necessary if clinical examination raises the suspicion of hip pathology.

\subsubsection{Total knee arthroplasty - Current designs}

Most current primary knee replacement designs fall into the category of unconstrained knee replacements. There are two design types in this category: the posterior cruciate retaining 
and the posterior cruciate substituting (or posterior stabilized) implants. Both types include a metal femoral component, a metal tibial component with a polyethylene insert (or an all polyethylene tibial component) and if used a polyethylene patella component. The implants can be cemented or uncemented.

The posterior cruciate retaining design is controversially thought to replicate knee kinematics more closely because the native posterior cruciate ligament causes femoral rollback. They have low conformity with a round femoral surface and a relatively flat tibial polyethylene surface.

The posterior cruciate substituting designs have increased conformity. They employ a tibial polyethylene post in the middle of the knee together with a cam situated between the femoral condyles. During flexion the femoral cam engages against the tibial post. With further flexion controlled mechanical rollback is achieved.

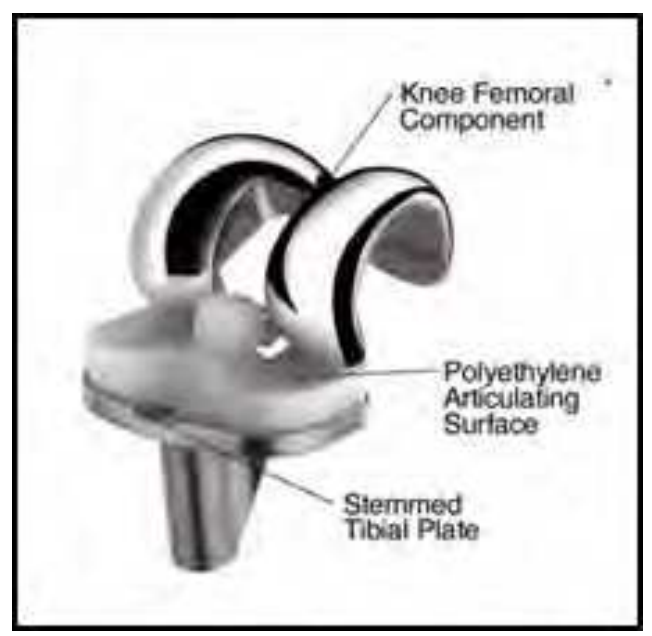

Fig. 6. Cruciate substituting Total Knee Replacement prosthesis

\subsubsection{Total knee arthroplasty - Surgical goals}

A pain free, mobile, stable joint replacement with a long life span is the overall aim of knee replacement surgery. The achievement of several biomechanical goals can contribute towards this overall aim. Implant design and surgical technique are crucial in how these goals are achieved.

\subsubsection{Restoration of mechanical axis}

The proximal tibia and distal femur are cut in such a way that at the end of the operation the mechanical axis of the limb should pass from the centre of the hip through the centre of the knee to the centre of the ankle. This allows the equal passage of forces through the joint replacement optimizing its longevity. [Fang 2009]

\subsubsection{Preserve the level of the joint line}

The femur and tibia are cut at a depth that is equal to the thickness of the prosthesis that is inserted. Optimal function of ligaments, muscles and tendons can be expected if the joint line level is preserved. 


\subsubsection{Soft tissue balancing in the coronal plane}

An osteoarthritic knee with a varus or valgus deformity has soft tissues that are contracted on one side of the joint and stretched on the other side. If the deformity is not corrected by the bony cuts, a soft tissue release is performed on the concave side of the deformity. If the knee is well balanced at the end of the procedure, load transmission should be approximately equal through both sides of the joint.

\subsubsection{Balancing the flexion and extension gaps in the sagittal plane}

At the end of the procedure, the gap between the tibia and femur should be the same in extension and in flexion. A gap that is too tight in extension or flexion will prevent full extension or flexion respectively. A gap too loose in extension will allow hyperextension of the knee; too loose in flexion will allow instability in flexion.

\subsubsection{Maintenance of $Q$ angle}

The most common complication in Total Knee replacement involves the patellofemoral articulation.

The $\mathrm{Q}$ angle is the angle formed by a line drawn from the Anterior Superior Iliac Spine to the central patella and a second line drawn from the central patella to the tibial tubercle. An increased $Q$ angle is a risk factor for patellar subluxation.

Positioning of the femoral, tibial and patella component (if used) all can influence the stability of the patellofemoral articulation.

\subsubsection{Total knee arthroplasty - Results}

Total knee arthroplasty is an effective treatment for advanced knee osteoarthritis, resulting in substantial improvement in patient function and health related quality of life. [Buly 1995] The success of the procedure can be judged by patient satisfaction and by the lifespan of the implant before a revision procedure is required. (Survivorship)

Patient satisfaction can be assessed by questionnaires. A study using data from the British National Joint Registry demonstrated $81.8 \%$ of 8095 patients were satisfied, $11.2 \%$ (906 of 8095 ) were unsure and 7\% (566 of 8095) were not satisfied with their new knee. [Baker 2007] The total condylar knee design continues to be successful. At 15 years follow up, survivorship can be expected to be as high as 95\%. [Ranawat 1993] [Ritter 2001].

\subsubsection{Total knee arthroplasty - Controversial topics and recent developments}

\subsubsection{Cemented versus uncemented fixation}

Cemented fixation of total knee replacement is a standard procedure with good long-term durability. Despite the predominance of cemented fixation, there is increasing interest in using cementless fixation. The principal advantage to using uncemented implants is the shorter operating times.

A meta-analysis compared the two techniques by outcome. [Gandhi 2009] For implant survival without aseptic loosening, cemented prostheses lasted longer. Both designs shared similar complications and produced similar results.

The advantages of cemented fixation are that it is less costly and gives immediate stable fixation, preventing early migration. [Nilsson 1999] Cemented fixation has the added advantage of filling in small voids, whereas uncemented fixation requires perfect bony cuts to allow a perfect fit between prosthesis and bone. 


\subsubsection{Cruciate retaining versus cruciate sacrificing design}

Good long-term results are reported in both posterior cruciate retaining (CR) and posterior cruciate substituting (PS) Total Knee Replacement designs. [Ritter 2007] [Bourne 2007]

The role of the posterior cruciate ligament (PCL) in total knee replacement remains controversial. Those in favour of retaining the PCL propose maintenance of normal knee kinematics, particularly with reference to femoral rollback. Others believe that the PCL's proprioceptive properties should encourage its retention. [Scott 1986] [Conditt 2004] [Insall 1988] [Swanik 2004] Those in favour of sacrificing the PCL argue that the ligament is degenerative in arthritic knees and that removing it makes soft tissue balancing more straight forward. If the PCL is excised, most surgeons will use a posterior cruciate substituting design, although this is not essential as long as a reasonably conforming insert is used. [Straw 2003] Proponents of the PS design argue that the central polyethylene post engages on the femoral cam during flexion providing mechanical femoral rollback. [Dennis 1996]The central post may also provide some additional stability in the anteroposterior plane and act as a secondary stabiliser to varus or valgus stress. [Matsuda 1996]

Multiple comparative studies have shown no demonstrable difference in knee scores, patient satisfaction or radiographic parameters. [Dorr 1988] [Clark 2001] [Tanzer 2002] A systematic literature review within the Cochrane framework [Jacobs 2005] identified an increased average range of motion in the posterior stabilised group (113 degrees) compared with the PCL retention group (105 degrees). No other differences were found. The review does not conclude superiority of one technique over the other.

\subsubsection{Patella resurfacing versus non-resurfacing}

Management of the patella in Total Knee Replacement for osteoarthritis remains controversial. Currently, there are three options available: Routine resurfacing, nonresurfacing and selective resurfacing. Proponents of patellar resurfacing propose that this procedure will decrease the incidence of anterior knee pain postoperatively and lower the risk of reoperation following Total Knee Replacement.

Some surgeons avoid routine resurfacing on the basis of a variety of complications that have been attributed to the procedure. These include instability of the patellofemoral joint, avascular necrosis, patellar fracture, patella tendon injury, aseptic loosening and polyethylene wear of the patella component. These complications although relatively uncommon have been associated with difficult revision procedures. [Barrack 1998] [Rand 2005]

Some surgeons opt to selectively resurface the patella, but it has been shown that the appearance of the articular cartilage is an unreliable predictor for a successful outcome. [Waters 2003]

There have been a substantial number of comparative studies on this subject. Indeed, several meta-analyses have collated this evidence, demonstrating a lower risk of reoperation for resurfaced implants, but not demonstrating firm evidence of superiority of one technique over the other. [Nizard 2005] [Forster 2004] [Pakos 2005] [Parvizi 2005] A critical appraisal of the available evidence suggests that patellar resurfacing reduces the risk of anterior knee pain and patella related reoperation, but found methodological limitations in all the studies examined. It concludes that no single option for patella treatment in total knee replacement is clearly superior. [Calvisi 2009] 


\subsubsection{Computer assisted surgery}

Over recent years, there has been considerable development in computer-assisted navigation systems for total knee replacement.

Current navigation systems are comprised of several components. An optical tracking system measures the position and orientation of optical reference frames that are attached to the femur and tibia, typically with bicortical threaded pins. The camera also tracks a stylus that the surgeon uses to digitize bony landmarks and an instrumented plate that records the position and orientation of the cutting blocks and bone surfaces. The navigation system is controlled by a computer and accompanying software. Anatomical reference frames are created that relate the position mad orientation of the optical reference frames to the underlying bony anatomy.

Although navigation in total knee replacement has increased in popularity over recent years, it remains controversial as to whether it is superior to traditional mechanical instrumentation techniques.

Most would accept that demonstrating improvements in results for a successful procedure such as total knee replacement is not easy.

The main arguments against the routine use of computer-assisted navigation relate to cost and time. The cost is variable, but has been shown to be in the region of an additional 200 to 1400 Euros per case, compared with the manual technique [Cerha 2009]. Cost effectiveness is difficult to judge until long-term outcome studies are available. It has been estimated that an annual reduction in revision rates of $2 \%$ would be required over 20 years in a centre performing 250 navigated total knee replacements per year, in order to be cost effective [Slover 2008]. Additional operating time is required. This has been demonstrated as being between 8 to 14 minutes per case. [Bäthis 2004] [Jenny 2005] [Haaker 2005]

A fundamental premise of computer-assisted navigation relates to one of the surgical goals of total knee replacement surgery. It has been proposed that more accurately restoring the mechanical axis of the limb will promote greater implant durability. Previous studies have suggested that restoring overall limb alignment to a mechanical axis of less than $3^{\circ}$ varus/valgus will improve the longevity of the implant [Jeffery 1991] [Ritter 1994]. Consequently, several studies have focused on this and demonstrated that the use of computer navigation can lead to a significant reduction in the number of outliers outside of this range. [Jenny 2005] [Bäthis 2004] A systematic review incorporating twenty nine studies comparing alignment outcomes in computer assisted knee replacements with conventional techniques demonstrated a $3^{\circ}$ varus/valgus malalignment occurred in $9 \%$ of computer assisted cases and $32 \%$ in conventional knee replacements.

More recently, this concept this has been contested with evidence to suggest that fifteen year survival of knee replacements is unaffected by variations in the postoperative limb mechanical axis. [Parratte 2010]

Some surgeons favour physiological reasons rather than alignment reasons in their reasoning to navigate a total knee replacement. Computer navigation techniques can avoid the need to instrument the femoral or tibial canals as with intramedullary jigs. Studies have demonstrated decreases in blood loss, systemic emboli and generalized systemic inflammatory response with the use of navigation techniques. [Kalairajah 2005] [Kalairajah 2006] [Church 2007] [Shen 2009].

Definitive conclusions regarding differences in clinical outcome between navigated and conventional techniques can only be made with long-term results of well-conducted 
randomised controlled trials. These are not yet available, but there is some evidence suggesting that rehabilitation is quicker and short-term function within the first postoperative year is improved with a greater accuracy in implant alignment. [Choong 2009] [Longstaff 2009]

\subsubsection{Mobile versus fixed bearing inserts}

Surgeons make a choice between monoblock all polyethylene tibial components and metallic tibial components with a modular polyethylene insert. The insert as described earlier can either be posterior stabilizing (with a post, to articulate with a cam on the femoral component) or cruciate retaining (no post). Either way, the insert can be of fixed bearing or mobile bearing design.

Mobile-bearing inserts can be further subdivided into rotating platform types or meniscal bearing types. A rotating platform rotates by utilizing a peg on its undersurface that fits into a socket on the base plate. In contrast to this, meniscal bearing inserts also allow anterior posterior translation of the insert over the base plate.

Theoretically, mobile bearing designs have greater total congruency of the femur/tibial articulation. This leads to less contact stress and potentially less polyethylene wear. Knee simulation studies have demonstrated less wear with rotating platform designs. [Mcewen 2001] The other proposed advantage is that the freedom of movement at the polyethylene/tibial tray interface should decrease the stresses at the tibial tray/bone interface.

There have been a large number of publications attempting to determine whether the theoretical advantages of a mobile bearing insert are transformed into clinical advantages. These studies consistently fail to demonstrate any significant advantage for either design. [Evans 2006] [Biau 2006] [Kim 2007] [Kim 2007a]

\subsubsection{Patient specific cutting blocks}

This new technique relies on patient specific cutting blocks. These are engineered by using a computer template of the patient's own anatomy. Preoperative imaging with a Magnetic Resonance Imaging scan and mechanical axis radiographs are used. These individualized cutting blocks allow precise bone resections to be made, allowing implantation of standard knee replacement implants. Advantages are a shortened operation time and a smaller surgical inventory requirement (sizes of implants determined preoperatively). Disadvantages are the additional costs for the preoperative imaging and the production of the custom made cutting blocks. Long-term results using this technique are awaited.

\subsubsection{Unicompartmental Knee Arthroplasty (UKA)}

UKA is the partial surface replacement of the knee joint. Osteoarthritic changes can be predominantly confined to one of the three compartments of the knee. In this scenario, a UKA can be performed in the medial tibiofemoral joint, the lateral tibiofemoral joint or the patellofemoral joint. By far the most common site for osteoarthritis in the knee is the medial tibiofemoral joint. The biggest experience to date with UKA has been with the medial tibiofemoral joint. Here, a metallic femoral component and a metallic tibial component replace the medial side of the knee joint. The components can be cemented or uncemented. In between the two metal components, a polyethylene insert is positioned. This can be a mobile bearing or a fixed bearing design. In the mobile bearing design, the polyethylene insert has a flat undersurface to allow it to slide over the flat tibial component. The top 
surface is concave allowing a congruent articulation with the spherical femoral component above. The proposed benefits of this articulation are larger contact areas; resulting in lower contact pressures and decreased polyethylene wear rates. The disadvantages of the mobile bearing design are that it is technically more challenging to implant and the potential risk for bearing dislocation. The fixed bearing design has a polyethylene insert which locks into the tibial tray. A meta-analysis pooling data from five studies concluded that there was no significant difference in outcome or complication rates between mobile and fixed bearing UKAs. [Smith 2009]

The ideal indications for UKA include unicompartmental osteoarthritis; age over 60 years; low demand patient; no obesity; range of motion arc over 90 degrees with less than 5 degrees fixed flexion contracture; less than 10 degrees of axial malalignment in the coronal plane which is passively correctable. [Borus 2008]

One perceived advantage of UKA over Total Knee Replacement is a less extensive surgical dissection. Generally, there is no need for eversion of the patella and the soft tissue disruption is less. Preservation of bone stock, decreased blood loss and an end result with more normal knee kinematics are also quoted as advantages. [Robinson 2003]

Unicompartmental knee arthroplasty (UKA), total knee arthroplasty (TKA) and high tibial osteotomy (HTO) may all be used to treat unicompartmental osteoarthritis, but they are often used for different patient groups. However, there is considerable overlap in indications for all three options.

A systematic review [Griffin 2007] focused on the safety and efficacy of UKA compared with TKA and HTO in unicompartmental osteoarthritis. Studies that compared UKA with either TKA or HTO were identified and included for review. They conclude that UKA is considered at least as safe as TKA and HTO. For function, UKA appears to be at least as efficacious as TKA and HTO. The survival of UKA compared with TKA and HTO could not be determined based on the available evidence.

The first published series of UKA documented a 70\% 10-year survival rate. [Marmor 1988] [Marmor 1988a]

Improvements in implant design; materials and instrumentation combined with clearer patient selection criteria may have been partially responsible for some of the better-reported results. Up to $98 \%$ survivorship has been reported at 10 years in both fixed and mobile bearing designs. [Berger 1999] [Murray 1998]

On the other hand a prospective study of 1819 patients from the Finnish Arthroplasty Register demonstrated an overall 10-year survival of $73 \%$ between four different implants. This supports the view of many, that the long-term survival of UKAs remains significantly poorer than that of TKA. [Koskinen 2007]

Isolated lateral compartment osteoarthritis of the knee is less common. Consequently, outcome studies reporting results of lateral UKA are less abundant. Results appear to be less predictable with a higher complication rate than the medial UKA. [Gunther 1996]

Isolated patellofemoral osteoarthritis occurs in approximately $10 \%$ of patients with knee osteoarthritis. There is often a previous diagnosis of trauma, patellar maltracking or trochlear dysplasia. Arthroplasty options include TKA with patellar resurfacing, TKA without patella resurfacing [Thompson 2001] and isolated patellofemoral replacement. The number of isolated patellofemoral replacements is increasing. The commonest complication identified is radiological progression of arthritis. [Ackroyd 2007] [Odumenya 2010] 


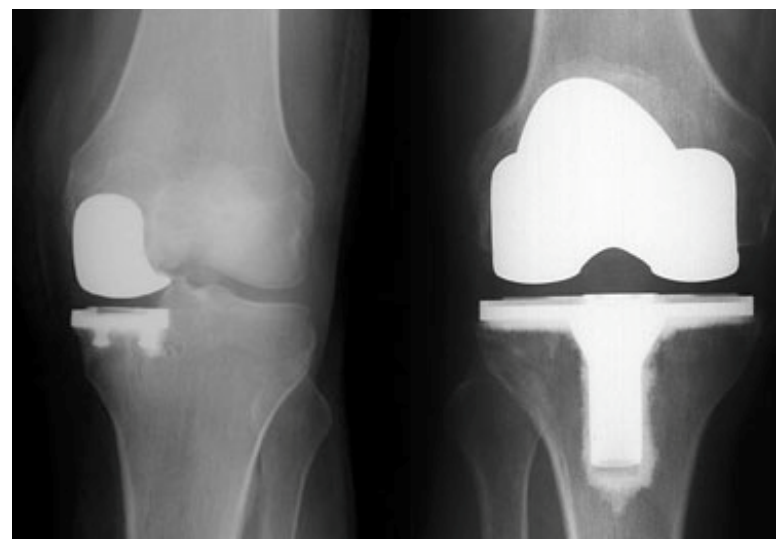

Fig. 7. Unicompartmental Knee Arthroplasty (UKA) and Total Knee Replacement (TKR)

\section{Conclusion}

Osteoarthritis of the knee is a common condition. The chances of developing symptoms increase with age. Initially treatment is with non-operative measures. Surgical options are considered when conservative measures have failed. We have discussed the options of arthroscopy, bone marrow stimulating techniques, chondrocyte transplantation, osteotomy and arthroplasty. Determining which of these procedures is most appropriate depends on a number of different variables. Age, comorbidities, patient activity levels and expectations, severity of symptoms and surgeon expertise and preference all contribute to the decision process.

Arthroscopic lavage and debridement is a procedure that is often carried out, but it does not alter the disease progression. Single compartment disease may be amenable to offloading osteotomy or unicompartmental knee arthroplasty. Total knee arthroplasty is a reliable treatment option for end stage osteoarthritis of the knee.

\section{References}

Ackroyd, C.E., Newman, J.H., Evans, R., Eldridge, J.D. \& Joslin, C.C., 2007, The Avon patellofemoral arthroplasty: five-year survivorship and functional results, The Journal of bone and joint surgery. British volume, 89(3), pp. 310-5.

Amendola, A. \& Bonasia, D.E., 2010, Results of high tibial osteotomy: review of the literature, International orthopaedics, 34(2), pp. 155-60.

Aqueskirchner, J.D., Bernau, A., Burkart, A.C. \& Imhoff, A.B., 2002, [Knee instability and varus malangulation - Simultaneous cruciate ligament reconstruction and osteotomy (Indication, planning and operative technique, results)], Zeitschrift für Orthopädie und ihre Grenzgebiete, 140(2), pp. 185-93.

Bae, D.K., Yoon, K.H. \& Song, S.J., 2006, Cartilage healing after microfracture in osteoarthritic knees, Arthroscopy: The Journal of Arthroscopic E Related Surgery, 22(4), pp. 367-74.

Baker, P.N., van der Meulen, J.H., Lewsey, J., Gregg, P.J. \& National Joint Registry for England and Wales, 2007, The role of pain and function in determining patient 
satisfaction after total knee replacement. Data from the National Joint Registry for England and Wales, The Journal of bone and joint surgery. British volume, 89(7), pp. 893-900.

Barrack, R.L., Matzkin, E., Ingraham, R., Engh, G. \& Rorabeck, C., 1998, Revision knee arthroplasty with patella replacement versus bony shell, Clinical orthopaedics and related research(356), pp. 139-43.

Basad, E., Ishaque, B., Bachmann, G., Stürz, H. \& Steinmeyer, J., 2010, Matrix-induced autologous chondrocyte implantation versus microfracture in the treatment of cartilage defects of the knee: a 2-year randomised study, Knee surgery, sports traumatology, arthroscopy : official journal of the ESSKA, 18(4), pp. 519-27.

Basad, E., Stürz, H. \& Steinmeyer, J., 2004, Die Behandlung chondraler Defekte mit MACI oder Microfracture--erste Ergebnisse einer vergleichenden klinischen Studie, Orthopädische Praxis, 40, pp. 6-10.

BÄTHIS, H., Perlick, L., Tingart, M., LÜRING, C. \& Grifka, J., 2004, CT-free computerassisted total knee arthroplasty versus the conventional technique: radiographic results of 100 cases, Orthopedics, 27(5), pp. 476-80.

Bentley, G., Biant, L.C., Carrington, R.W., Akmal, M., Goldberg, A., Williams, A.M., Skinner, J.A. \& Pringle, J., 2003, A prospective, randomised comparison of autologous chondrocyte implantation versus mosaicplasty for osteochondral defects in the knee, The Journal of bone and joint surgery. British volume, 85(2), pp. 223-30.

Berger, R.A., Nedeff, D.D., Barden, R.M., Sheinkop, M.M., Jacobs, J.J., Rosenberg, A.G. \& Galante, J.O., 1999, Unicompartmental knee arthroplasty. Clinical experience at 6to 10-year followup, Clinical orthopaedics and related research(367), pp. 50-60.

Bert, J.M. \& Maschka, K., 1989, The arthroscopic treatment of unicompartmental gonarthrosis: a five-year follow-up study of abrasion arthroplasty plus arthroscopic debridement and arthroscopic debridement alone, Arthroscopy : the journal of arthroscopic \& related surgery : official publication of the Arthroscopy Association of North America and the International Arthroscopy Association, 5(1), pp. 25-32.

Biau, D., Mullins, M.M., Judet, T. \& Piriou, P., 2006, Mobile versus fixed-bearing total knee arthroplasty: mid-term comparative clinical results of 216 prostheses, Knee surgery, sports traumatology, arthroscopy : official journal of the ESSKA, 14(10), pp. 927-33.

Borus, T. \& Thornhill, T., 2008, Unicompartmental knee arthroplasty, The Journal of the American Academy of Orthopaedic Surgeons, 16(1), pp. 9-18.

Bourne, R.B., Laskin, R.S. \& Guerin, J.S., 2007, Ten-year results of the first 100 Genesis II total knee replacement procedures, Orthopedics, 30(8 Suppl), pp. 83-5.

Brittberg, M. \& Peterson, L., 2003, Articular cartilage engineering with autologous chondrocyte transplantation: a review of recent developments, The Journal of Bone and Joint Surgery, 85(Supplement 3), p. 109.

Brittberg, M., Lindahl, A., Nilsson, A., Ohlsson, C., Isaksson, O. \& Peterson, L., 1994, Treatment of deep cartilage defects in the knee with autologous chondrocyte transplantation, The New England journal of medicine, 331(14), pp. 889-95.

Broughton, N.S., Newman, J.H. \& Baily, R.A., 1986, Unicompartmental replacement and high tibial osteotomy for osteoarthritis of the knee. A comparative study after 5-10 years' follow-up, The Journal of bone and joint surgery. British volume, 68(3), pp. 44752. 
Brouwer, R.W., Bierma-Zeinstra, S.M.A., Van Raaij, T.M. \& Verhaar, J.A.N., 2006, Osteotomy for medial compartment arthritis of the knee using a closing wedge or an opening wedge controlled by a Puddu plate: a one-year randomised, controlled study, Journal of Bone and Joint Surgery-British Volume, 88(11), p. 1454.

Brouwer, R.W., Raaij van, T.M., Bierma-Zeinstra, S.M., Verhagen, A.P., Jakma, T.S. \& Verhaar, J.A., 2007, Osteotomy for treating knee osteoarthritis, Cochrane database of systematic reviews (Online)(3), p. CD004019.

Buly, R.L. \& Sculco, T.P., 1995, Recent advances in total knee replacement surgery, Current opinion in rheumatology, 7(2), pp. 107-13.

Burman, M.S., FINKELSTEIN, H. \& MAYER, L.E.O., 1934, Arthroscopy of the knee joint, The Journal of Bone and Joint Surgery, 16(2), p. 255.

Calvisi, V., Camillieri, G. \& Lupparelli, S., 2009, Resurfacing versus nonresurfacing the patella in total knee arthroplasty: a critical appraisal of the available evidence, Archives of orthopaedic and trauma surgery, 129(9), pp. 1261-70.

Cerha, O., Kirschner, S., Günther, K.P. \& Lützner, J., 2009, [Cost analysis for navigation in knee endoprosthetics], Der Orthopäde, 38(12), pp. 1235-40.

Chang, R.W., Falconer, J., Stulberg, S.D., Arnold, W.J., Manheim, L.M. \& Dyer, A.R., 1993, A randomized, controlled trial of arthroscopic surgery versus closed-needle joint lavage for patients with osteoarthritis of the knee, Arthritis and rheumatism, 36(3), pp. 289-96.

Choong, P.F., Dowsey, M.M. \& Stoney, J.D., 2009, Does accurate anatomical alignment result in better function and quality of life? Comparing conventional and computerassisted total knee arthroplasty, The Journal of arthroplasty, 24(4), pp. 560-9.

Church, J.S., Scadden, J.E., Gupta, R.R., Cokis, C., Williams, K.A. \& Janes, G.C., 2007, Embolic phenomena during computer-assisted and conventional total knee replacement, The Journal of bone and joint surgery. British volume, 89(4), pp. 481-5.

Clark, C.R., Rorabeck, C.H., MacDonald, S., MacDonald, D., Swafford, J. \& Cleland, D., 2001, Posterior-stabilized and cruciate-retaining total knee replacement: a randomized study, Clinical orthopaedics and related research(392), pp. 208-12.

Conditt, M.A., Noble, P.C., Bertolusso, R., Woody, J. \& Parsley, B.S., 2004, The PCL significantly affects the functional outcome of total knee arthroplasty, The Journal of arthroplasty, 19(7 Suppl 2), pp. 107-12.

Coventry, M.B., 1965, Osteotomy of the upper portion of the tibia for degenerative arthritis of the knee. a preliminary report, The Journal of bone and joint surgery. American volume, 47 , pp. 984-90.

Coventry, M.B., 1979, Upper tibial osteotomy for gonarthrosis. The evolution of the operation in the last 18 years and long term results, The Orthopedic clinics of North America, 10(1), pp. 191-210.

Coventry, M.B., 1984, Upper tibial osteotomy, Clinical orthopaedics and related research, 182, p. 46.

Coventry, M.B. \& Bowman, P.W., 1982, Long-term results of upper tibial osteotomy for degenerative arthritis of the knee, Acta orthopaedica Belgica, 48(1), p. 139.

Coventry, M.B., Ilstrup, D.M. \& Wallrichs, S.L. 1993, Proximal tibial osteotomy. A critical long-term study of eighty-seven cases, in The Journal of Bone and Joint Surgery, JBJS, p. 196. 
Dennis, D.A., Komistek, R.D., Hoff, W.A. \& Gabriel, S.M., 1996, In vivo knee kinematics derived using an inverse perspective technique, Clinical orthopaedics and related research(331), pp. 107-17.

Dettoni, F., Bonasia, D.E., Castoldi, F., Bruzzone, M., Blonna, D. \& Rossi, R., 2010, High tibial osteotomy versus unicompartmental knee arthroplasty for medial compartment arthrosis of the knee: a review of the literature, The Iowa orthopaedic journal, 30, pp. 131-40.

Dorr, L.D., Ochsner, J.L., Gronley, J. \& Perry, J., 1988, Functional comparison of posterior cruciate-retained versus cruciate-sacrificed total knee arthroplasty, Clinical orthopaedics and related research(236), pp. 36-43.

Dozin, B., Malpeli, M., Cancedda, R., Bruzzi, P., Calcagno, S., Molfetta, L., Priano, F., Kon, E. \& Marcacci, M., 2005, Comparative evaluation of autologous chondrocyte implantation and mosaicplasty: a multicentered randomized clinical trial, Clinical journal of sport medicine : official journal of the Canadian Academy of Sport Medicine, 15(4), pp. 220-6.

Erggelet, C., Sittinger, M. \& Lahm, A., 2003, The arthroscopic implantation of autologous chondrocytes for the treatment of full-thickness cartilage defects of the knee joint, Arthroscopy : the journal of arthroscopic \& related surgery : official publication of the Arthroscopy Association of North America and the International Arthroscopy Association, 19(1), pp. 108-10.

Evans, M.C., Parsons, E.M., Scott, R.D., Thornhill, T.S. \& Zurakowski, D., 2006, Comparative flexion after rotating-platform vs fixed-bearing total knee arthroplasty, The Journal of arthroplasty, 21(7), pp. 985-91.

Fang, D.M., Ritter, M.A. \& Davis, K.E., 2009, Coronal alignment in total knee arthroplasty: just how important is it? The Journal of arthroplasty, 24(6 Suppl), pp. 39-43.

Felson, D.T., Naimark, A., Anderson, J., Kazis, L., Castelli, W. \& Meenan, R.F., 1987, The prevalence of knee osteoarthritis in the elderly. The Framingham Osteoarthritis Study, Arthritis and rheumatism, 30(8), pp. 914-8.

Flecher, X., Parratte, S., Aubaniac, J.M. \& Argenson, J.N.A., 2006, A 12-28-year followup study of closing wedge high tibial osteotomy, Clinical orthopaedics and related research, 452, p. 91.

Forster, M.C., 2004, Patellar resurfacing in total knee arthroplasty for osteoarthritis: a systematic review, The Knee, 11(6), pp. 427-30.

Friedman, M.J., Berasi, C.C., Fox, J.M., Del Pizzo, W., Snyder, S.J. \& Ferkel, R.D., 1984, Preliminary results with abrasion arthroplasty in the osteoarthritic knee, Clinical orthopaedics and related research(182), pp. 200-5.

Gandhi, R., Tsvetkov, D., Davey, J.R. \& Mahomed, N.N., 2009, Survival and clinical function of cemented and uncemented prostheses in total knee replacement: a meta-analysis, The Journal of bone and joint surgery. British volume, 91(7), pp. 889-95.

Gillogly, S.D., Myers, T.H. \& Reinold, M.M., 2006, Treatment of full-thickness chondral defects in the knee with autologous chondrocyte implantation, The Journal of orthopaedic and sports physical therapy, 36(10), pp. 751-64.

Griffin, T., Rowden, N., Morgan, D., Atkinson, R., Woodruff, P. \& Maddern, G., 2007, Unicompartmental knee arthroplasty for the treatment of unicompartmental osteoarthritis: a systematic study, ANZ journal of surgery, 77(4), pp. 214-21. 
Gudas, R., Kalesinskas, R.J., Kimtys, V., Stankevicius, E., Toliusis, V., Bernotavicius, G. \& Smailys, A., 2005, A prospective randomized clinical study of mosaic osteochondral autologous transplantation versus microfracture for the treatment of osteochondral defects in the knee joint in young athletes, Arthroscopy : the journal of arthroscopic $\mathcal{E}$ related surgery : official publication of the Arthroscopy Association of North America and the International Arthroscopy Association, 21(9), pp. 1066-75.

Gunston, F.H., 1971, Polycentric knee arthroplasty. Prosthetic simulation of normal knee movement, The Journal of bone and joint surgery. British volume, 53(2), pp. 272-7.

Gunther, T.V., Murray, D.W., Miller, R., Wallace, D.A., Carr, A.J., O'Connor, J.J., McLardySmith, P. \& Goodfellow, J.W., 1996, Lateral unicompartmental arthroplasty with the Oxford meniscal knee, The Knee, 3(1-2), pp. 33-9.

Haaker, R.G., Stockheim, M., Kamp, M., Proff, G., Breitenfelder, J. \& Ottersbach, A., 2005, Computer-assisted navigation increases precision of component placement in total knee arthroplasty, Clinical orthopaedics and related research(433), pp. 152-9.

Hangody, L. \& Füles, P., 2003, Autologous osteochondral mosaicplasty for the treatment of full-thickness defects of weight-bearing joints: ten years of experimental and clinical experience, The Journal of bone and joint surgery. American volume, 85-A Suppl 2, pp. 25-32.

Harris, J.D., Siston, R.A., Pan, X. \& Flanigan, D.C., 2010, Autologous chondrocyte implantation: a systematic review, The Journal of bone and joint surgery. American volume, 92(12), pp. 2220-33.

Harris, W.R. \& Kostuik, J.P., 1970, High tibial osteotomy for osteo-arthritis of the knee, The Journal of bone and joint surgery. American volume, 52(2), pp. 330-6.

Horas, U., Pelinkovic, D., Herr, G., Aigner, T. \& Schnettler, R., 2003, Autologous chondrocyte implantation and osteochondral cylinder transplantation in cartilage repair of the knee joint. A prospective, comparative trial, The Journal of bone and joint surgery. American volume, 85-A(2), pp. 185-92.

Hubbard, M.J.S., 1996, Articular debridement versus washout for degeneration of the medial femoral condyle: a five-year study, Journal of Bone and Joint Surgery-British Volume, 78(2), p. 217.

Insall, J.N., 1988, Presidential address to The Knee Society. Choices and compromises in total knee arthroplasty, Clinical orthopaedics and related research(226), pp. 43-8.

Ivarsson, I., Myrnerts, R. \& Gillquist, J., 1990, High tibial osteotomy for medial osteoarthritis of the knee. A 5 to 7 and 11 year follow-up, The Journal of bone and joint surgery. British volume, 72(2), pp. 238-44.

Jackson, J.P. \& Waugh, W., 1961, Tibial osteotomy for osteoarthritis of the knee, Journal of Bone and Joint Surgery-British Volume, 43(4), p. 746.

Jacobs, W.C., Clement, D.J. \& Wymenga, A.B., 2005, Retention versus removal of the posterior cruciate ligament in total knee replacement: a systematic literature review within the Cochrane framework, Acta orthopaedica, 76(6), pp. 757-68.

Jeffery, R.S., Morris, R.W. \& Denham, R.A., 1991, Coronal alignment after total knee replacement, The Journal of bone and joint surgery. British volume, 73(5), pp. 709-14.

Jenny, J.Y., Clemens, U., Kohler, S., Kiefer, H., Konermann, W. \& Miehlke, R.K., 2005, Consistency of implantation of a total knee arthroplasty with a non-image-based navigation system: a case-control study of 235 cases compared with 235 conventionally implanted prostheses, The Journal of arthroplasty, 20(7), pp. 832-9. 
Kalairajah, Y., Cossey, A.J., Verrall, G.M., Ludbrook, G. \& Spriggins, A.J., 2006, Are systemic emboli reduced in computer-assisted knee surgery?: a prospective, randomised, clinical trial, Journal of Bone and Joint Surgery-British Volume, 88(2), p. 198.

Kalairajah, Y., Simpson, D., Cossey, A.J., Verrall, G.M. \& Spriggins, A.J., 2005, Blood loss after total knee replacement: effects of computer-assisted surgery, Journal of Bone and Joint Surgery-British Volume, 87(11), p. 1480.

Karabatsos, B., Mahomed, N.N. \& Maistrelli, G.L., 2002, Functional outcome of total knee arthroplasty after high tibial osteotomy, Canadian journal of surgery. Journal canadien de chirurgie, 45(2), pp. 116-9.

Karataglis, D. \& Learmonth, D.J., 2005, Management of big osteochondral defects of the knee using osteochondral allografts with the MEGA-OATS technique, The Knee, 12(5), pp. 389-93.

Karolin, R., 2011, Current Surgical Treatment of Knee Osteoarthritis, Arthritis, 2011.

Kazakos, K.J., Chatzipapas, C., Verettas, D., Galanis, V., Xarchas, K.C. \& Psillakis, I., 2008, Mid-term results of total knee arthroplasty after high tibial osteotomy, Archives of orthopaedic and trauma surgery, 128(2), pp. 167-73.

Kim, Y.H., Kim, D.Y. \& Kim, J.S., 2007a, Simultaneous mobile- and fixed-bearing total knee replacement in the same patients. A prospective comparison of mid-term outcomes using a similar design of prosthesis, The Journal of bone and joint surgery. British volume, 89(7), pp. 904-10.

Kim, Y.H., Yoon, S.H. \& Kim, J.S., 2007b, The long-term results of simultaneous fixedbearing and mobile-bearing total knee replacements performed in the same patient, The Journal of bone and joint surgery. British volume, 89(10), pp. 1317-23.

Knutsen, G., Drogset, J.O., Engebretsen, L., Grøntvedt, T., Isaksen, V., Ludvigsen, T.C., Roberts, S., Solheim, E., Strand, T. \& Johansen, O., 2007, A randomized trial comparing autologous chondrocyte implantation with microfracture. Findings at five years, The Journal of bone and joint surgery. American volume, 89(10), pp. 2105-12.

Knutsen, G., Engebretsen, L., Ludvigsen, T.C., Drogset, J.O., Grøntvedt, T., Solheim, E., Strand, T., Roberts, S., Isaksen, V. \& Johansen, O., 2004, Autologous chondrocyte implantation compared with microfracture in the knee. A randomized trial, The Journal of bone and joint surgery. American volume, 86-A(3), pp. 455-64.

Kon, E., Gobbi, A., Filardo, G., Delcogliano, M., Zaffagnini, S. \& Marcacci, M., 2009, Arthroscopic second-generation autologous chondrocyte implantation compared with microfracture for chondral lesions of the knee: prospective nonrandomized study at 5 years, The American journal of sports medicine, 37(1), pp. 33-41.

Koskinen, E., Paavolainen, P., Eskelinen, A., Pulkkinen, P. \& Remes, V., 2007, Unicondylar knee replacement for primary osteoarthritis: a prospective follow-up study of 1,819 patients from the Finnish Arthroplasty Register, Acta orthopaedica, 78(1), pp. 128-35.

Kreuz, P.C., Erggelet, C., Steinwachs, M.R., Krause, S.J., Lahm, A., Niemeyer, P., Ghanem, N., Uhl, M. \& Südkamp, N., 2006, Is microfracture of chondral defects in the knee associated with different results in patients aged 40 years or younger? Arthroscopy: The Journal of Arthroscopic \& Related Surgery, 22(11), pp. 1180-6.

Krishnan, S.P., Skinner, J.A., Bartlett, W., Carrington, R.W., Flanagan, A.M., Briggs, T.W. \& Bentley, G., 2006, Who is the ideal candidate for autologous chondrocyte implantation? The Journal of bone and joint surgery. British volume, 88(1), pp. 61-4. 
Laupattarakasem, W., Laopaiboon, M., Laupattarakasem, P. \& Sumananont, C., 2008, Arthroscopic debridement for knee osteoarthritis, Cochrane database of systematic reviews (Online)(1), p. CD005118.

Lobenhoffer, P. \& Agneskirchner, J.D., 2003, Improvements in surgical technique of valgus high tibial osteotomy, Knee surgery, sports traumatology, arthroscopy : official journal of the ESSKA, 11(3), pp. 132-8.

Lohmander, L.S., 2003, Tissue engineering of cartilage: do we need it, can we do it, is it good and can we prove it? Novartis Foundation symposium, 249, pp. 2-10; discussion 10-6, 170-4, 239-41.

Longstaff, L.M., Sloan, K., Stamp, N., Scaddan, M. \& Beaver, R., 2009, Good alignment after total knee arthroplasty leads to faster rehabilitation and better function, The Journal of arthroplasty, 24(4), pp. 570-8.

Magnuson, P.B., 1941, Joint debridement. Surgical treatment of degenerative arthritis, Surg Gynecol Obstet, 73(1).

Marmor, L., 1988a, Unicompartmental arthroplasty of the knee with a minimum ten-year follow-up period, Clinical orthopaedics and related research(228), pp. 171-7.

Marmor, L., 1988b, Unicompartmental knee arthroplasty. Ten- to 13-year follow-up study, Clinical orthopaedics and related research(226), pp. 14-20.

Matsuda, S., Whiteside, L.A., White, S.E. \& McCarthy, D.S., 1996, TRANSACTIONS OF THE ANNUAL MEETING-ORTHOPAEDIC RESEARCH SOCIETY, Knee kinematics of posterior cruciate ligament sacrificed total knee arthroplasty. pp. 722-.

Matsusue, Y., Yamamuro, T. \& Hama, H., 1993, Arthroscopic multiple osteochondral transplantation to the chondral defect in the knee associated with anterior cruciate ligament disruption, Arthroscopy: The Journal of Arthroscopic \& Related Surgery, 9(3), pp. 318-21.

Matthews, L.S., Goldstein, S.A., Malvitz, T.A., Katz, B.P. \& Kaufer, H., 1988, Proximal tibial osteotomy. Factors that influence the duration of satisfactory function, Clinical orthopaedics and related research(229), pp. 193-200.

McEwen, H.M., Fisher, J., Goldsmith, A.A., Auger, D.D., Hardaker, C. \& Stone, M.H., 2001, Wear of fixed bearing and rotating platform mobile bearing knees subjected to high levels of internal and external tibial rotation, Journal of materials science. Materials in medicine, 12(10-12), pp. 1049-52.

Meachim, G. \& Roberts, C., 1971, Repair of the joint surface from subarticular tissue in the rabbit knee, Journal of anatomy, 109(Pt 2), pp. 317-27.

Microfracture technique for full thickness chondral defects: technique and clinical results, .

Mitchell, N. \& Shepard, N., 1976, The resurfacing of adult rabbit articular cartilage by multiple perforations through the subchondral bone, The Journal of Bone and Joint Surgery, 58(2), p. 230.

Mont, M.A., Alexander, N., Krackow, K.A. \& Hungerford, D.S., 1994, Total knee arthroplasty after failed high tibial osteotomy, The Orthopedic clinics of North America, 25(3), pp. 515-25.

Moseley, J.B., O'Malley, K., Petersen, N.J., Menke, T.J., Brody, B.A., Kuykendall, D.H., Hollingsworth, J.C., Ashton, C.M. \& Wray, N.P., 2002, A controlled trial of arthroscopic surgery for osteoarthritis of the knee, The New England journal of medicine, 347(2), pp. 81-8. 
Murray, D.W., Goodfellow, J.W. \& O'Connor, J.J., 1998, The Oxford medial unicompartmental arthroplasty: a ten-year survival study, The Journal of bone and joint surgery. British volume, 80(6), pp. 983-9.

Naudie, D., Bourne, R.B., Rorabeck, C.H. \& Bourne, T.J., 1999, The Install Award. Survivorship of the high tibial valgus osteotomy. A 10- to -22-year followup study, Clinical orthopaedics and related research(367), pp. 18-27.

Nilsson, K.G., Kärrholm, J., Carlsson, L. \& Dalén, T., 1999, Hydroxyapatite coating versus cemented fixation of the tibial component in total knee arthroplasty: prospective randomized comparison of hydroxyapatite-coated and cemented tibial components with 5-year follow-up using radiostereometry, The Journal of arthroplasty, 14(1), pp. 9-20.

Nizard, R.S., Biau, D., Porcher, R., Ravaud, P., Bizot, P., Hannouche, D. \& Sedel, L., 2005, A meta-analysis of patellar replacement in total knee arthroplasty, Clinical orthopaedics and related research(432), pp. 196-203.

Odumenya, M., Costa, M.L., Parsons, N., Achten, J., Dhillon, M. \& Krikler, S.J., 2010, The Avon patellofemoral joint replacement: Five-year results from an independent centre, The Journal of bone and joint surgery. British volume, 92(1), pp. 56-60.

Ogilvie-Harris, D.J. \& Fitsialos, D.P., 1991, Arthroscopic management of the degenerative knee, Arthroscopy : the journal of arthroscopic \& related surgery : official publication of the Arthroscopy Association of North America and the International Arthroscopy Association, 7(2), pp. 151-7.

Outerbridge, H.K., Outerbridge, A.R. \& Outerbridge, R.E., 1995, The use of a lateral patellar autologous graft for the repair of a large osteochondral defect in the knee, The Journal of bone and joint surgery. American volume, 77(1), pp. 65-72.

Outerbridge, R.E., 1961, The etiology of chondromalacia patellae, Journal of Bone and Joint Surgery-British Volume, 43(4), p. 752.

Pakos, E.E., Ntzani, E.E. \& Trikalinos, T.A., 2005, Patellar resurfacing in total knee arthroplasty. A meta-analysis, The Journal of bone and joint surgery. American volume, 87(7), pp. 1438-45.

Paley, D. \& Pfeil, J., 2000, [Principles of deformity correction around the knee], Der Orthopäde, 29(1), pp. 18-38.

Parratte, S., Pagnano, M.W., Trousdale, R.T. \& Berry, D.J., 2010, Effect of postoperative mechanical axis alignment on the fifteen-year survival of modern, cemented total knee replacements, The Journal of bone and joint surgery. American volume, 92(12), pp. 2143-9.

Parvizi, J., Rapuri, V.R., Saleh, K.J., Kuskowski, M.A., Sharkey, P.F. \& Mont, M.A., 2005, Failure to resurface the patella during total knee arthroplasty may result in more knee pain and secondary surgery, Clinical orthopaedics and related research, 438, pp. 191-6.

Potter, H.G. \& Chong, l.e. .R., 2009, Magnetic resonance imaging assessment of chondral lesions and repair, The Journal of bone and joint surgery. American volume, 91 Suppl 1, pp. 126-31.

Pridie, K.H., 1959, A method of resurfacing osteoarthritic knee joints, The Journal of bone and joint surgery. British volume, 41(3), pp. 618-9. 
Ranawat, C.S., Flynn, W.F., Saddler, S., Hansraj, K.K. \& Maynard, M.J., 1993, Long-term results of the total condylar knee arthroplasty. A 15-year survivorship study, Clinical orthopaedics and related research(286), pp. 94-102.

Rand, J.A., 2005, Extensor mechanism complications after total knee arthroplasty, Instructional course lectures, 54, pp. 241-50.

Ritter, M.A., Berend, M.E., Meding, J.B., Keating, E.M., Faris, P.M. \& Crites, B.M., 2001, Long-term followup of anatomic graduated components posterior cruciateretaining total knee replacement, Clinical orthopaedics and related research(388), pp. 51-7.

Ritter, M.A., Faris, P.M., Keating, E.M. \& Meding, J.B., 1994, Postoperative alignment of total knee replacement its effect on survival, Clinical orthopaedics and related research, 299, p. 153.

Ritter, M.A., Lutgring, J.D., Davis, K.E., Faris, P.M. \& Berend, M.E., 2007, Total knee arthroplasty effectiveness in patients 55 years old and younger: osteoarthritis vs. rheumatoid arthritis, The Knee, 14(1), pp. 9-11.

Roberts, S., McCall, I.W., Darby, A.J., Menage, J., Evans, H., Harrison, P.E. \& Richardson, J.B., 2003, Autologous chondrocyte implantation for cartilage repair: monitoring its success by magnetic resonance imaging and histology, Arthritis research $\mathcal{E}$ therapy, 5(1), pp. R60-73.

Robinson, B.J., Price, A.J., Murray, D.M. \& McLardy-Smith, P., 2003, Indications and results of unicompartmental arthroplasty, Current Opinion in Orthopaedics, 14(1), p. 41.

Rudan, J.F. \& Simurda, M.A., 1990, High tibial osteotomy. A prospective clinical and roentgenographic review, Clinical orthopaedics and related research(255), pp. 251-6.

Saris, D.B., Vanlauwe, J., Victor, J., Almqvist, K.F., Verdonk, R., Bellemans, J., Luyten, F.P. \& TIG/ACT/01/2000\&EXT Study Group, 2009, Treatment of symptomatic cartilage defects of the knee: characterized chondrocyte implantation results in better clinical outcome at 36 months in a randomized trial compared to microfracture, The American journal of sports medicine, 37 Suppl 1, pp. 10S-9S.

Saris, D.B., Vanlauwe, J., Victor, J., Haspl, M., Bohnsack, M., Fortems, Y., Vandekerckhove, B., Almqvist, K.F., Claes, T., Handelberg, F., Lagae, K., van der Bauwhede, J., Vandenneucker, H., Yang, K.G., Jelic, M., Verdonk, R., Veulemans, N., Bellemans, J. \& Luyten, F.P., 2008, Characterized chondrocyte implantation results in better structural repair when treating symptomatic cartilage defects of the knee in a randomized controlled trial versus microfracture, The American journal of sports medicine, 36(2), pp. 235-46.

Scott, R.D. \& Volatile, T.B., 1986, Twelve years' experience with posterior cruciate-retaining total knee arthroplasty, Clinical orthopaedics and related research(205), pp. 100-7.

Shaw, J.A. \& Moulton, M.J., 1996, High tibial osteotomy: an operation based on a spurious mechanical concept. A theoretic treatise, American journal of orthopedics (Belle Mead, NJ), 25(6), p. 429.

Shen, H., Zhang, N., Zhang, X. \& Ji, W., 2009, C-reactive protein levels after 4 types of arthroplasty, Acta orthopaedica, 80(3), pp. 330-3.

Slover, J.D., Tosteson, A.N., Bozic, K.J., Rubash, H.E. \& Malchau, H., 2008, Impact of hospital volume on the economic value of computer navigation for total knee replacement, The Journal of bone and joint surgery. American volume, 90(7), pp. 1492-500. 
Smith, T.O., Hing, C.B., Davies, L. \& Donell, S.T., 2009, Fixed versus mobile bearing unicompartmental knee replacement: a meta-analysis, Orthopaedics $\mathcal{E}$ traumatology, surgery E research: OTSR, 95(8), pp. 599-605.

Spector, T.D., Cicuttini, F., Baker, J.R., Loughlin, J.A. \& Hart, D.J., 1996, Genetic influences on osteoarthritis in females: a study of twins, Br. Med. J, 312, pp. 940-4.

Sprenger, T.R. \& Doerzbacher, J.F., 2003, Tibial osteotomy for the treatment of varus gonarthrosis. Survival and failure analysis to twenty-two years, The Journal of bone and joint surgery. American volume, 85-A(3), pp. 469-74.

Staubli, A.E., De Simoni, C., Babst, R. \& Lobenhoffer, P., 2003, TomoFix: a new LCP-concept for open wedge osteotomy of the medial proximal tibia--early results in 92 cases, Injury, 34 Suppl 2, pp. B55-62.

Steadman, J.R., Briggs, K.K., Rodrigo, J.J., Kocher, M.S., Gill, T.J. \& Rodkey, W.G., 2003a, Outcomes of microfracture for traumatic chondral defects of the knee: average 11year follow-up, Arthroscopy : the journal of arthroscopic \& related surgery : official publication of the Arthroscopy Association of North America and the International Arthroscopy Association, 19(5), pp. 477-84.

Steadman, J.R., Miller, B.S., Karas, S.G., Schlegel, T.F., Briggs, K.K. \& Hawkins, R.J., 2003b, The microfracture technique in the treatment of full-thickness chondral lesions of the knee in National Football League players, The journal of knee surgery, 16(2), pp. 83-6.

Steadman, J.R., Rodkey, W.G. \& Briggs, K.K., 2002, Microfracture to treat full-thickness chondral defects: surgical technique, rehabilitation, and outcomes, The journal of knee surgery, 15(3), p. 170.

Steadman, J.R., Rodkey, W.G., Singleton, S.B. \& Briggs, K.K., 1997, Microfracture technique forfull-thickness chondral defects: Technique and clinical results, Operative techniques in orthopaedics, 7(4), pp. 300-4.

Straw, R., Kulkarni, S., Attfield, S. \& Wilton, T.J., 2003, Posterior cruciate ligament at total knee replacement. Essential, beneficial or a hindrance? The Journal of bone and joint surgery. British volume, 85(5), pp. 671-4.

Stukenborg-Colsman, C., Wirth, C.J., Lazovic, D. \& Wefer, A., 2001, High tibial osteotomy versus unicompartmental joint replacement in unicompartmental knee joint osteoarthritis: 7-10-year follow-up prospective randomised study, The Knee, 8(3), pp. 187-94.

Swanik, C.B., Lephart, S.M. \& Rubash, H.E., 2004, Proprioception, kinesthesia, and balance after total knee arthroplasty with cruciate-retaining and posterior stabilized prostheses, The Journal of bone and joint surgery. American volume, 86-A(2), pp. 328-34.

Tanzer, M., Smith, K. \& Burnett, S., 2002, Posterior-stabilized versus cruciate-retaining total knee arthroplasty: balancing the gap, The Journal of arthroplasty, 17(7), pp. 813-9.

Thompson, N.W., Ruiz, A.L., Breslin, E. \& Beverland, D.E., 2001, Total knee arthroplasty without patellar resurfacing in isolated patellofemoral osteoarthritis, The Journal of arthroplasty, 16(5), pp. 607-12.

Valdes, A.M., Spector, T.D., Tamm, A., Kisand, K., Doherty, S.A., Dennison, E.M., Mangino, M., Tamm, A., Kerna, I., Hart, D.J., Wheeler, M., Cooper, C., Lories, R.J., Arden, N.K. \& Doherty, M., 2010, Genetic variation in the SMAD3 gene is associated with hip and knee osteoarthritis, Arthritis and rheumatism, 62(8), pp. 2347-52. 
van Raaij, T., Reijman, M., Furlan, A. \& Verhaar, J.A.N., 2009, Total knee arthroplasty after high tibial osteotomy. A systematic review, BMC musculoskeletal disorders, 10(1), p. 88 .

Vasiliadis, H.S. \& Wasiak, J., 2010, Autologous chondrocyte implantation for full thickness articular cartilage defects of the knee, Cochrane database of systematic reviews (Online)(10), p. CD003323.

Virolainen, P. \& Aro, H.T., 2004, High tibial osteotomy for the treatment of osteoarthritis of the knee: a review of the literature and a meta-analysis of follow-up studies, Archives of orthopaedic and trauma surgery, 124(4), pp. 258-61.

Walldius, B., 1953, Arthroplasty of the knee joint using an acrylic prosthesis, Acta orthop. scand, 23, p. 121.

Waters, T.S. \& Bentley, G., 2003, Patellar resurfacing in total knee arthroplasty. A prospective, randomized study, The Journal of bone and joint surgery. American volume, $85-\mathrm{A}(2)$, pp. 212-7.

Zhang, W., Moskowitz, R.W., Nuki, G., Abramson, S., Altman, R.D., Arden, N., BiermaZeinstra, S., Brandt, K.D., Croft, P., Doherty, M., Dougados, M., Hochberg, M., Hunter, D.J., Kwoh, K., Lohmander, L.S. \& Tugwell, P., 2007, OARSI recommendations for the management of hip and knee osteoarthritis, part I: critical appraisal of existing treatment guidelines and systematic review of current research evidence, Osteoarthritis and cartilage / OARS, Osteoarthritis Research Society, 15(9), pp. 981-1000.

Zhang, W., Moskowitz, R.W., Nuki, G., Abramson, S., Altman, R.D., Arden, N., BiermaZeinstra, S., Brandt, K.D., Croft, P., Doherty, M., Dougados, M., Hochberg, M., Hunter, D.J., Kwoh, K., Lohmander, L.S. \& Tugwell, P., 2008, OARSI recommendations for the management of hip and knee osteoarthritis, Part II: OARSI evidence-based, expert consensus guidelines, Osteoarthritis and cartilage / OARS, Osteoarthritis Research Society, 16(2), pp. 137-62.

Zhang, W., Nuki, G., Moskowitz, R.W., Abramson, S., Altman, R.D., Arden, N.K., BiermaZeinstra, S., Brandt, K.D., Croft, P., Doherty, M., Dougados, M., Hochberg, M., Hunter, D.J., Kwoh, K., Lohmander, L.S. \& Tugwell, P., 2010, OARSI recommendations for the management of hip and knee osteoarthritis: part III: Changes in evidence following systematic cumulative update of research published through January 2009, Osteoarthritis and cartilage / OARS, Osteoarthritis Research Society, 18(4), pp. 476-99.

Zhang, W., Robertson, J., Jones, A.C., Dieppe, P.A. \& Doherty, M., 2008, The placebo effect and its determinants in osteoarthritis: meta-analysis of randomised controlled trials, Annals of the rheumatic diseases, 67(12), p. 1716. 


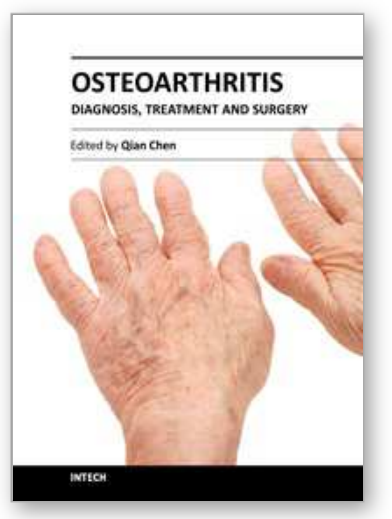

\author{
Osteoarthritis - Diagnosis, Treatment and Surgery \\ Edited by Prof. Qian Chen
}

ISBN 978-953-51-0168-0

Hard cover, 404 pages

Publisher InTech

Published online 02, March, 2012

Published in print edition March, 2012

Osteoarthritis is one of the most debilitating diseases affecting millions of people worldwide. However, there is no FDA approved disease modifying drug specifically for OA. Surgery remains an effective last resort to restore the function of the joints. As the aging populations increase worldwide, the number of OA patients increases dramatically in recent years and is expected to increase in many years to come. This is a book that summarizes recent advance in OA diagnosis, treatment, and surgery. It includes wide ranging topics from the cutting edge gene therapy to alternative medicine. Such multifaceted approaches are necessary to develop novel and effective therapy to cure $O A$ in the future. In this book, different surgical methods are described to restore the function of the joints. In addition, various treatment options are presented, mainly to reduce the pain and enhance the life quality of the OA patients.

\title{
How to reference
}

In order to correctly reference this scholarly work, feel free to copy and paste the following:

J.R. Lewis and R.L. Carey Smith (2012). Surgery for Osteoarthritis of the Knee, Osteoarthritis - Diagnosis, Treatment and Surgery, Prof. Qian Chen (Ed.), ISBN: 978-953-51-0168-0, InTech, Available from: http://www.intechopen.com/books/osteoarthritis-diagnosis-treatment-and-surgery/surgery-for-osteoarthritis-ofthe-knee

\section{INTECH}

open science | open minds

\author{
InTech Europe \\ University Campus STeP Ri \\ Slavka Krautzeka 83/A \\ 51000 Rijeka, Croatia \\ Phone: +385 (51) 770447 \\ Fax: +385 (51) 686166 \\ www.intechopen.com
}

\author{
InTech China \\ Unit 405, Office Block, Hotel Equatorial Shanghai \\ No.65, Yan An Road (West), Shanghai, 200040, China \\ 中国上海市延安西路65号上海国际贵都大饭店办公楼 405 单元 \\ Phone: +86-21-62489820 \\ Fax: +86-21-62489821
}


(C) 2012 The Author(s). Licensee IntechOpen. This is an open access article distributed under the terms of the Creative Commons Attribution 3.0 License, which permits unrestricted use, distribution, and reproduction in any medium, provided the original work is properly cited. 